\title{
Discovery of Intermediates of lacZ - Galactosidase Catalyzed Hydrolysis Using dDNP NMR
}

Kjeldsen, Christian; Ardenkjær-Larsen, Jan Henrik; Duus, Jens $\varnothing$.

Published in:

Journal of the American Chemical Society

Link to article, DOI:

10.1021/jacs.7b13358

Publication date:

2018

Document Version

Peer reviewed version

Link back to DTU Orbit

Citation (APA):

Kjeldsen, C., Ardenkjær-Larsen, J. H., \& Duus, J. Ø. (2018). Discovery of Intermediates of lacZ -Galactosidase Catalyzed Hydrolysis Using dDNP NMR. Journal of the American Chemical Society, 140(8), 3030-3034. https://doi.org/10.1021/jacs.7b13358

\section{General rights}

Copyright and moral rights for the publications made accessible in the public portal are retained by the authors and/or other copyright owners and it is a condition of accessing publications that users recognise and abide by the legal requirements associated with these rights.

- Users may download and print one copy of any publication from the public portal for the purpose of private study or research.

- You may not further distribute the material or use it for any profit-making activity or commercial gain

- You may freely distribute the URL identifying the publication in the public portal 


\title{
Discovery of intermediates of lacZ $\beta$-galactosidase catalyzed hydroly- sis using dDNP NMR
}

\author{
Christian Kjeldsen ${ }^{[\mathrm{a}]}$, Jan Henrik Ardenkjær-Larsen ${ }^{[\mathrm{b}]}$ and Jens Øllgaard Duus*[a] \\ ${ }^{[a]}$ Department of Chemistry, Technical University of Denmark, 2800 Kgs. Lyngby, Denmark. ${ }^{[b]}$ Department of Electrical En- \\ gineering, Center for Hyperpolarization in Magnetic Resonance, Technical University of Denmark, Kgs. Lyngby, Denmark
}

Supporting Information Placeholder

\begin{abstract}
Using dissolution dynamic nuclear polarization, the sensitivity of single scan solution state ${ }^{13} \mathrm{C}$ NMR can be improved up to four order of magnitude. In this study, the enzyme lacZ $\beta$ galactosidase from $E$. coli. was subjected to hyperpolarized substrate, and previously unknown reaction intermediates were observed, including a 1,1-linked disaccharide. The enzyme is known for making 1,6-transglycosylation, producing products like allolactose, that are also substrates. To analyze the kinetics, a simple kinetic model was developed and used to determine relative transglycosylation and hydrolysis rates of each of the intermediates, and the novel transglycosylation intermediates were determined as better substrates than the 1,6-linked one, explaining their transient nature. These findings suggest that hydrolysis and transglycosylation might be more complex than previously described.
\end{abstract}

\section{Introduction}

The increased understanding of the roles of carbohydrates in biology has led to development of carbohydrate based vaccines, diagnostics, therapeutics and prebiotics, but the field as a whole is held back by the difficulties from carbohydrate production. ${ }^{1,2}$ Enzymatic production of carbohydrates, which can be performed under mild conditions with high selectivity and specificity, is as such an area of great interest, and increased understanding of the mechanisms and intermediates of carbohydrate converting enzymes is essential to advance the field.

As intermediates in enzymatic reactions are often low-populated and short lived they can be quite difficult to detect and even more difficult to quantify or identify. For carbohydrates that is often even more so the case, as they do not have any fluorophores or chromophores, unless added synthetically, which yields little to no information on intermediates, but can be used to determine kinetics. However, while NMR spectroscopy is an excellent tool for identifying carbohydrate structures, it suffers from low sensitivity compared to most other analytical methods, resulting in long acquisition times. Using dissolution dynamic nuclear polarization (dDNP) the sensitivity of single scan solution NMR can be increased by up to four orders of magnitude. ${ }^{3}$

Conventional NMR spectroscopy has been used to study enzymatic reactions at equilibrium or for competition studies, ${ }^{4}$ and for glycosidases it is possible to determine whether the enzyme has a retaining or inverting mechanism. ${ }^{5}$ Using dDNP NMR it is possible to observe low-populated reaction intermediates, and examples include enzymatic reactions, ${ }^{6}$ polymerization reactions ${ }^{7}$ and metalcatalyzed reactions $^{8}$. In the first of these studies, two enzymes were used to monitor the conversion of $\left[1-{ }^{13} \mathrm{C}\right]$ acetate to $\left[1-{ }^{13} \mathrm{C}\right]$ acetyl- coenzyme A, and low-populated intermediate species were observed. ${ }^{6}$ The second study showed the utilization of dDNP NMR to examine the anionic polymerization of styrene, including intermediates, and also served as an example of a natural abundance probe being utilized for dDNP NMR. ${ }^{7}$ The third study also serves as an example of dDNP NMR for monitoring carbohydrate conversion, and the presence of an open-chain configuration of glucose bound to the molybdate-catalyst was detected. ${ }^{8}$ These studies all demonstrated the use of dDNP NMR to observe and describe reaction intermediates, and applying the method for glycosidases represents the possibility to further understand the mechanisms and transglycosylation abilities of the enzymes.

However, most carbohydrates possess poor properties for hyperpolarization, as they have few or no quaternary positions with long $\mathrm{T}_{1}$ relaxation. Exceptions to this are ketoses such as fructose, in which the anomeric position, which is also usually the position of interest, is quaternary with a long $\mathrm{T}_{1}$, and consequently fructose has been used for in vivo murine studies. ${ }^{9}$ For aldoses it is necessary to utilize ${ }^{2} \mathrm{H}$ labelling to elongate the $\mathrm{T}_{1}$ of the positions of interest, and $\left[\mathrm{U}-{ }^{2} \mathrm{H} ; \mathrm{U}-{ }^{13} \mathrm{C}\right]$ glucose has been used for several studies, ${ }^{8,10-13}$ but only one of these focused on the mechanisms of a single enzyme, namely phosphorylation of glucose by hexokinase. ${ }^{13}$

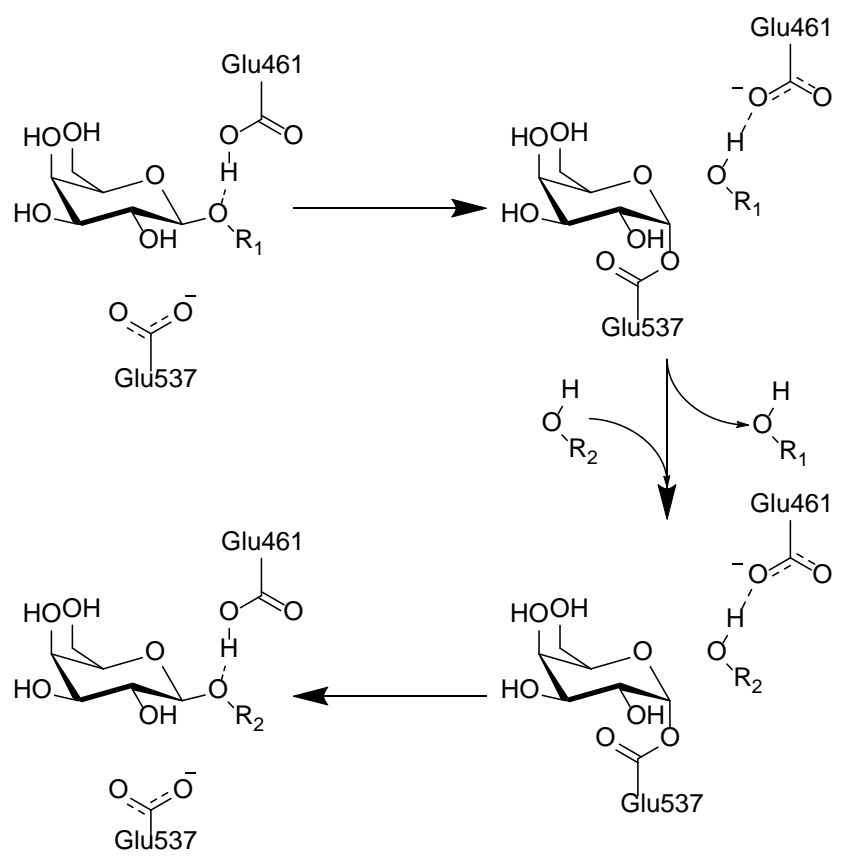


Scheme 1: General double displacement reaction mechanism of retaining glycosidases ${ }^{14}$ with $\operatorname{lacZ} \beta$-galactosidase as example. Glu537 is the nucleophile residue and Glu461 is the acid/base residue. If $R_{2}=H$ (water) the enzyme is hydrolyzing the substrate, otherwise it is transglycosylating.

Here we demonstrate the utility of dDNP NMR for increasing the understanding of carbohydrate converting enzymes, and the enzyme chosen as model enzyme is the lacZ $\beta$-galactosidase, as it is well characterized. ${ }^{15,16}$ The enzyme has a retaining mechanism, illustrated in scheme 1 , and the natural substrate is probably lactose, ${ }^{17}$ but ortho- or para-nitrophenyl $\beta$-D-galactopyranosides are often used in biochemical studies as they are good substrates and release nitrophenols detectable at low concentrations using UV/VIS spectroscopy. This also suits our method quite nicely, as the nitrophenyl contains quaternary carbons enabling experiment optimization with natural abundance before using labelled substrate. The enzyme is known to do transglycosylation to form allolactose from lactose, and the reported transglycosylation products are only 1,6-linked. ${ }^{15,18,19}$ Theoretically this was found to be the only viable product with glucose as acceptor. ${ }^{20}$

\section{Methods}

The dDNP was carried out on samples containing $o$-nitrophenyl $\beta$-D- $\left[1-{ }^{13} \mathrm{C} ; 1-{ }^{2} \mathrm{H}\right]$ galactopyranoside (Galp-onp) $(1.4 \mathrm{M})$ in DMSO with OX063 trityl radical (18 mM). The samples, 35-45 $\mu \mathrm{L}$, were polarized for at least 120 min using a HyperSense (Oxford Instruments) operating at $3.35 \mathrm{~T}$ and $<1.4 \mathrm{~K}$ with a $94 \mathrm{GHz}$ microwave source. The dissolution was performed using $5.0 \mathrm{~mL}$ of $175^{\circ}$ $\mathrm{C}$ aqueous $\mathrm{pH} 7.4$ phosphate buffer $(50 \mathrm{mM})$ and approximately $0.5 \mathrm{~mL}$ was manually injected into the NMR tube containing the enzyme, approximately $9 \mathrm{u}$ per $\mathrm{mM}$ substrate, and the acquisition started. The concentration of substrate was approximately $10 \mathrm{mM}$ after mixing with the enzyme. Any addition of acceptor was done prior to mixing with enzyme to a final concentration of approximately $175 \mathrm{mM}$. The manual transfer time was approximately $5 \mathrm{~s}$ from dissolution to acquisition start, and the time from started mixing of substrate and enzyme to acquisition start was approximately $0.5 \mathrm{~s}$.

The NMR acquisition was carried out at $310 \mathrm{~K}$ and $400 \mathrm{MHz}$ (DirectDrive console, Agilent, $100.5 \mathrm{MHz}$ for ${ }^{13} \mathrm{C}$ ) using 100 scans of $20^{\circ}$ flip angles using 32768 points with a repetition time of $2 \mathrm{~s}$. In the first scan, a signal enhancement of 10000-12000 times was observed corresponding to $8-10 \%$ polarization. The NMR data was acquired with VnmrJ 4.2 (Agilent), processed using TopSpin 3.5 (Bruker) and data analysis was performed using Matlab R2015a (MathWorks). The fitting was performed by minimizing the squared difference between the integrals and the model using the Matlab functions fmincon and ode45. Synthesis of isotope labelled substrate is described in the supporting information. The starting material, $\left[1-{ }^{13} \mathrm{C} ; 1-{ }^{2} \mathrm{H}\right]$ galactose with $98 \% 2 \mathrm{H}$ and $99 \% 13 \mathrm{C}$, was purchased from Omicron and a thermal NMR spectrum is shown in figure S2.

\section{Results and discussion}

Using natural abundance $o$-nitrophenyl $\beta$-D-galactopyranoside, which has long $T_{1}$ relaxation times of the quaternary positions of the aromatic ring, it was possible to optimize the hyperpolarization conditions for dDNP and the subsequent enzymatic measurements. Following this, the use of doubly labelled $o$-nitrophenyl $\beta$-D-[1${ }^{13} \mathrm{C} ; 1-{ }^{2} \mathrm{H}$ ]galactopyranoside (Galp-onp) as substrate allowed the monitoring of the anomeric position of the galactosides, as shown in figure 1. The labelled substrate was synthesized in four steps from labelled galactose (Omicron).
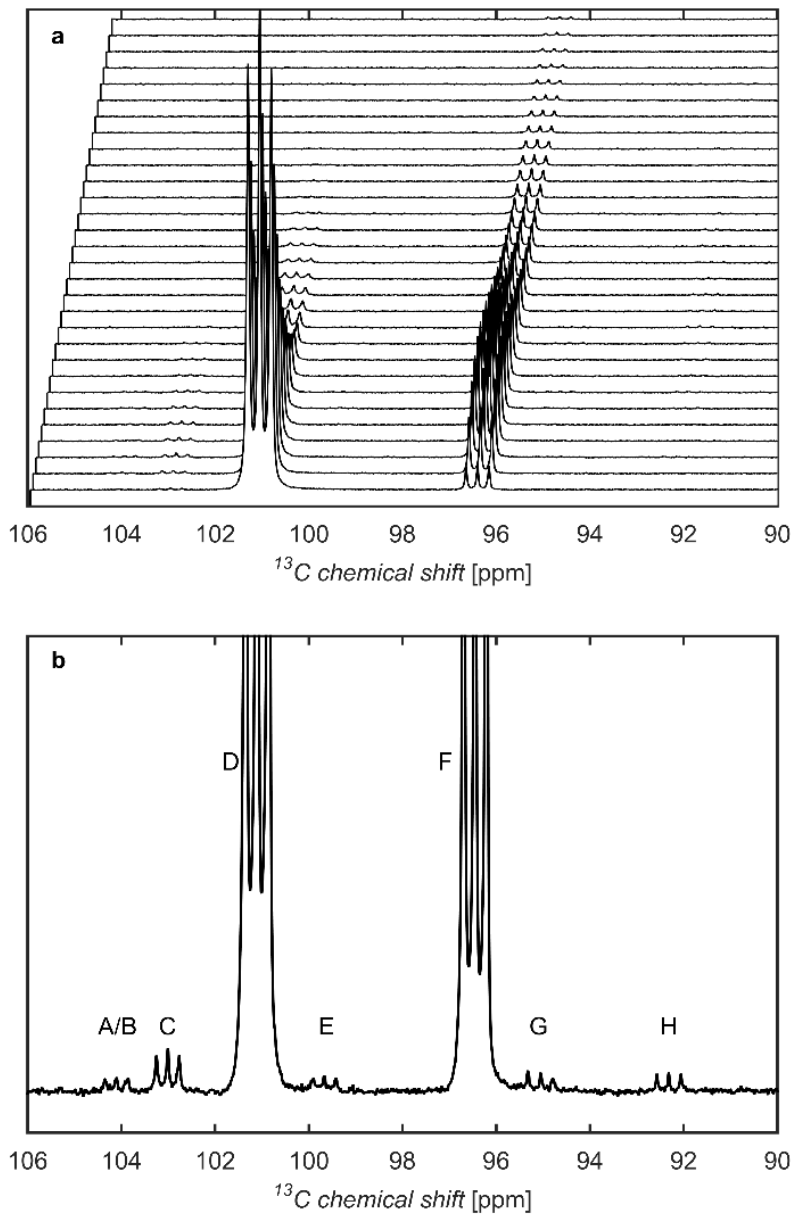

Figure 1. a: The first 30 spectra of doubly labelled Galp-onp enzymatic hydrolysis. The repetition time is $2 \mathrm{~s}$ and each spectrum is shifted $0.06 \mathrm{ppm}$ upfield. b: The sum of spectra 5 to 10 . A: $\beta$-Galp1,3-Gal, B: $\beta$-Galp-1,4-Gal, C: $\beta$-Galp-1,6-Gal, D: $\beta$-Galp-onp, E: $\beta$-Galp-1,1- $\beta$-Galp, F: $\beta$-Galp, G: $\alpha$-Galf and $H: \alpha$-Galp.

At these conditions, shown in figure 1, the enzyme is primarily hydrolyzing the substrate, as there is limited access to acceptor. To promote the transglycosylation activity of the enzyme, an excess of galactose was added to act as acceptor, resulting in a large increase in the signals corresponding to non-reducing $\beta$-galactopyranosides, see figure 2 . An overview of all the species discussed in the following sections is shown in scheme 2 . 

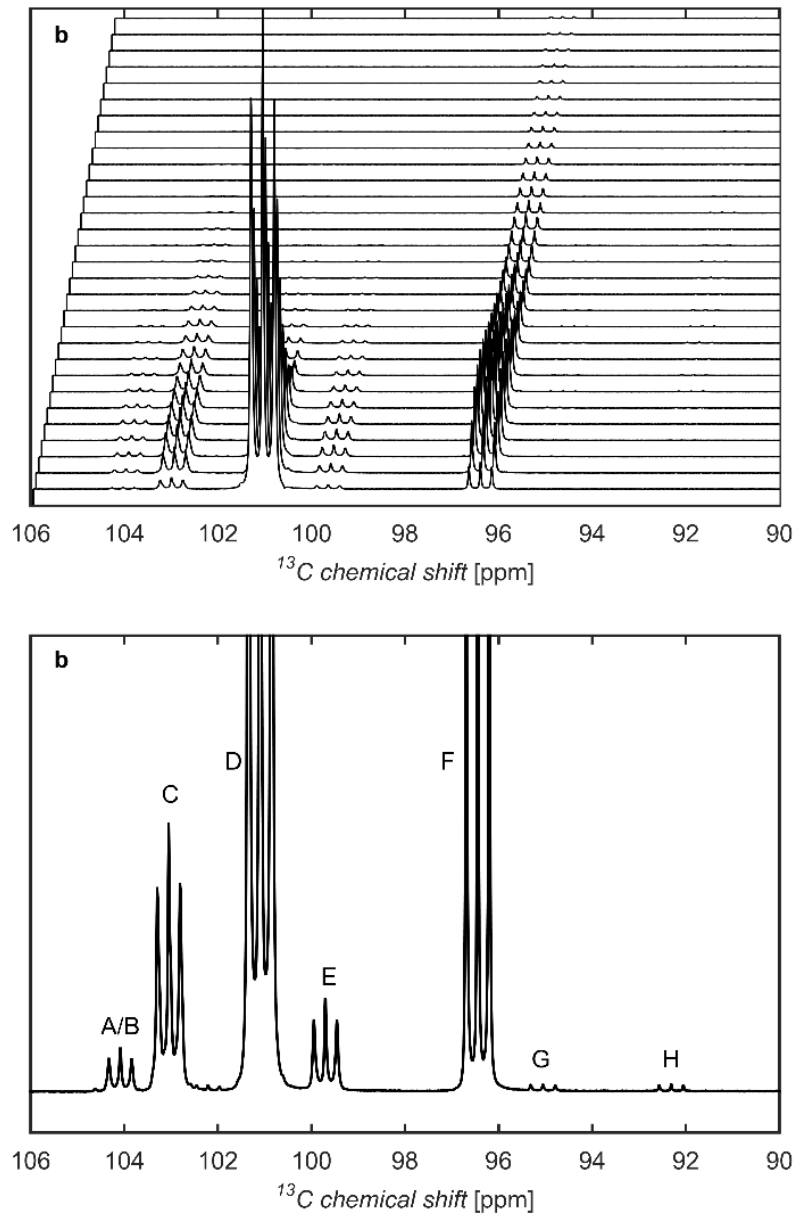

Figure 2. a: The first 30 spectra of doubly labelled Galp-onp enzymatic hydrolysis with added acceptor. The repetition time is $2 \mathrm{~s}$ and each spectrum is shifted $0.06 \mathrm{ppm}$ upfield. $\mathbf{b}$ : The sum of spectra 1 to 10 . The labels are the same as those in figure $1 \mathrm{~b}$.

The three signals with increased intensity, corresponding to compound $\mathbf{A} / \mathbf{B}, \mathbf{C}$ and $\mathbf{E}$, were assigned based on chemical shift comparison with literature. The largest of the three signals, corresponding to $\mathbf{C}$, was determined to be from $\beta$-Galp-1,6-Gal, ${ }^{21}$ which was also the expected product. Slightly downfield of this signal is $\mathbf{A} / \mathbf{B}$, which was determined to arise from either $\beta$-Galp-1,3-Gal, $\beta$-Galp1,4-Gal or both, as the anomeric position from both linkages have very similar chemical shift, ${ }^{22}$ and is thus referred to as a 1,3/4-linkage. The last of the three major transglycosylation product peaks, corresponding to $\mathbf{E}$, was quite far upfield for a $\beta$-Galp, and was determined as having a 1,1-linkage. ${ }^{23}$ To confirm this, 1 -O-methyl galactopyranoside was used as acceptor, which caused the signal corresponding to the 1,1-linkage to almost disappear from the spectra, as shown in the supporting information figure S1. The signal corresponding to the 1,1-linkage was still observed, albeit at a much lower intensity, and was likely produced using the gal released from hydrolysis as acceptor. 


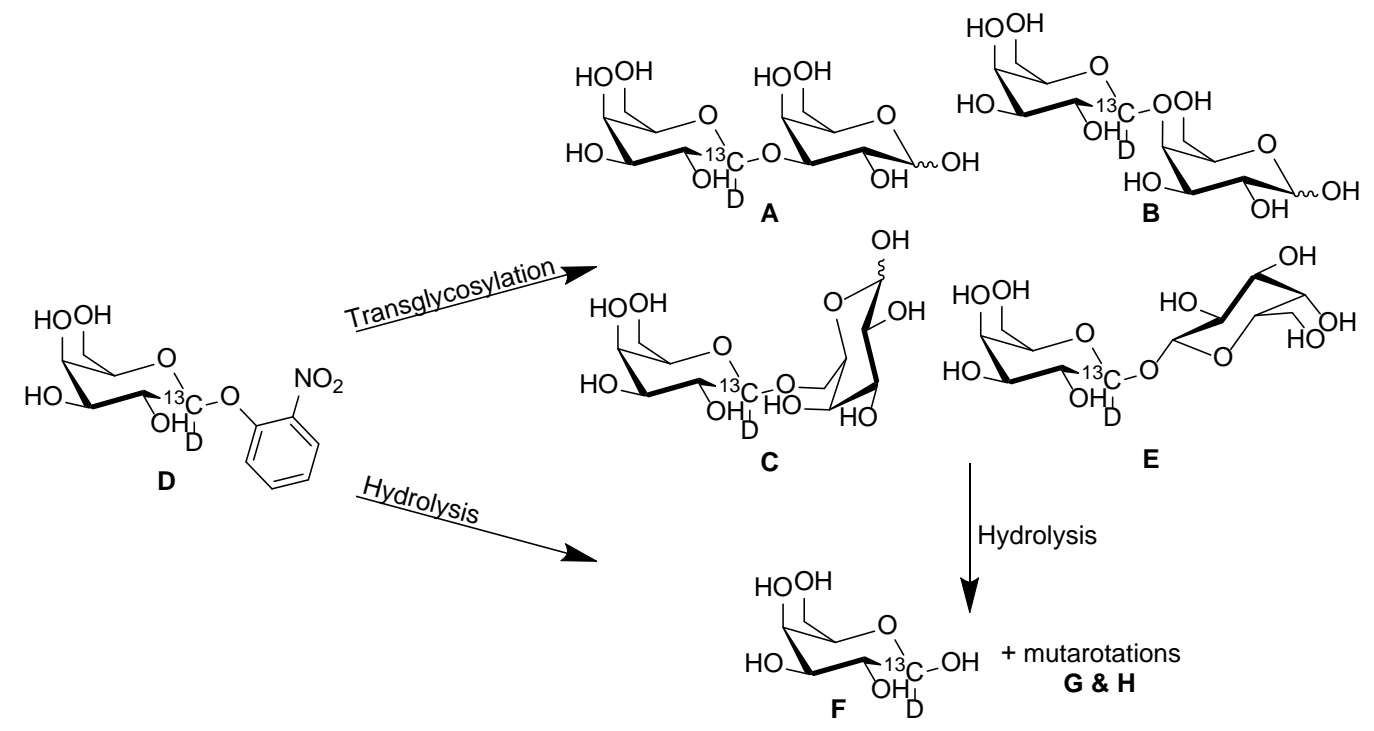

Scheme 2: Overview of the enzymatic reaction and the different species observed in the spectra. The lettering corresponds to those in figure 1 and 2 . Due to the retaining mechanism of the enzyme, illustrated in scheme 1 , the released galactose is of $\beta$ configuration, and the other configurations observed are formed via mutarotation.

Whether free galactose or one of the $\beta$-galactosides acts as the acceptor should have very limited effect upon the chemical shift of the donor or acceptor anomeric position, with the exception of the 1,1-linkage. Furthermore, the anomeric configuration of the acceptor should have little to no impact on the chemical shift of the donor anomeric position, again with the 1,1-linkage being the exception, where a $\beta$-anomeric glycopyranoside would be expected to have quite a large difference in chemical shift depending on the anomeric configuration of the aglycon of the 1,1-linkage. ${ }^{23}$ Following this, it stands to reason that the 1,1-linked $\beta$-Galp labelled as $\mathbf{D}$ in figure 1,2 and scheme 2 would indeed be a $\beta$-Galp-1,1- $\beta$-Galp. While the experiment with the added acceptor could have either $\alpha$ or $\beta$-Galp as acceptor, the experiment performed with no added acceptor only have minute amounts of $\alpha$-Galp until the mutarotation have had the time to equilibrate, and thus only $\beta$-Galp-1,1- $\beta$-Galp can be formed on the time-scale of the experiment. The chemical shift differs by approximately 1 ppm compared to the 1,1-linked $\beta$ galactopyranosides described by Koto et al. (1980), ${ }^{23}$ but this could be due to difference in referencing and isotope effect. The promiscuous nature of the enzyme could perhaps explain the formation of this 1,1-linkage, as the enzyme is known to hydrolyze almost any $\beta$-galactopyranoside. However, as no 1,2 -linkage nor $\alpha$-configuration of the 1,1-linked products were observed, there is some preference towards some of the nucleophilic groups present on the acceptor. It is possible that the $\beta-1,4$ and 6 positions are the most favored, as they are all accessible from the same side of the ring.

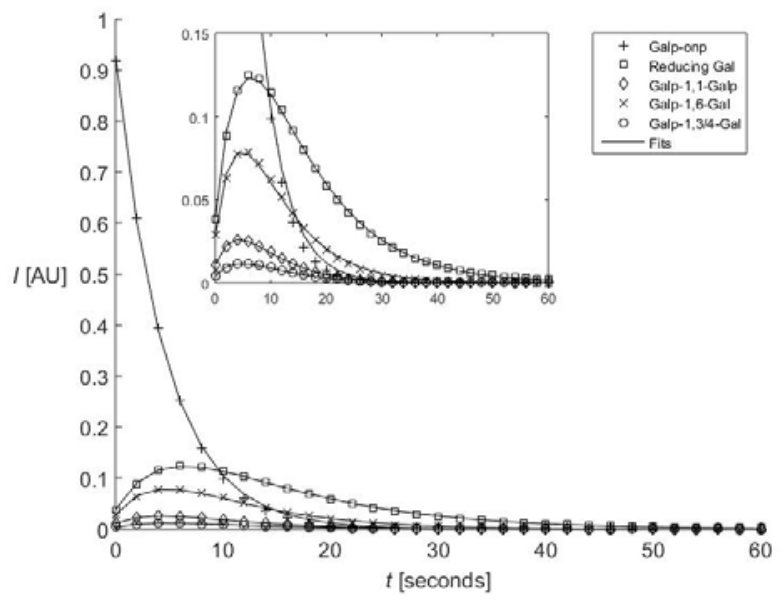

Figure 3. Peak integrals (in arbitrary units) of the five major species plotted over time with the models described in scheme 3 and 4 added. The insert is a zoom.

By plotting the integrals of each peak as a function of time, shown in figure 3 , the relative transglycosylation rates of the three intermediate products can be determined by comparing the maximum intensity of each, which leads to the approximation that the 1,6-linkage is formed 3.0 times faster than the 1,1-linkage and 6.9 times faster than the 1,3/4-linkage. However, the hydrolysis rates are a bit more difficult to determine, as the signal loss due to hydrolysis and polarization loss are both exponential decay. To extract approximate hydrolysis rates from the data, a kinetic model of the enzyme reaction was developed, similar to other kinetic studies utilizing dDNP NMR. ${ }^{24,25}$ Based on the seven reactions in scheme 3 the five equations in scheme 4 was devised. It is only the hyperpolarized doubly labelled anomeric positions that can be observed, and as such the results does not differentiate between di-, tri-, or oligosaccharides, as they would overlap in chemical shift, and thus whenever a reducing end is present in the model, it might be from free galactose or from a larger sugar. 


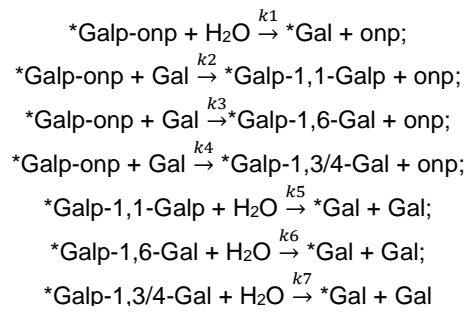

Scheme 3. The seven reactions used for the kinetics model. The * marks the doubly labelled anomeric position used for monitoring. All non-reducing galactosides have $\beta$-configuration due to the retaining mechanism of the enzyme.

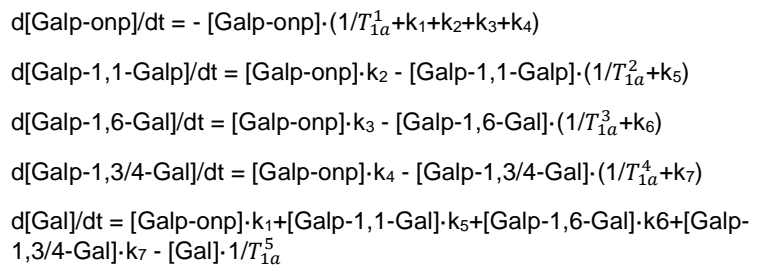

Scheme 4. The five equations used for the model. $T_{1 a}$ are the apparent $T_{1}$ relaxation times, which includes the polarization loss from NMR flip angles.

From these equations, the best fit to each of the five data series were found. The apparent $T_{1}$ relaxation for the reducing Gal was constrained by measuring it on the last few data points after the signal from the different substrates have decayed away, which gave values between $10.5 \mathrm{~s}$ and $11.4 \mathrm{~s}$ across the repetitions. Similarly, the apparent $\mathrm{T}_{1}$ relaxations for the four substrates are constrained to 7.5-8.5 s, based on measurements on Galp-onp without enzyme. Finally, any transglycosylation forming one disaccharide from another has been disregarded in the model. In figure 3 the fits are plotted alongside the data, and in figure 4 the fits are plotted with the contributions from the decay of polarization removed, meaning only the enzymatic reactions are left. Using the fit it was possible to determine the relative transglycosylation rates and verify the rates determined by comparing maximum intensities. It was determined that the $\beta$-Galp-1,1- $\beta$-Galp was a far better substrate compared to $\beta$-Galp-1,6-Gal or $\beta$-Galp-1,3/4-Gal, which was hydrolyzed at more similar rates. The relative production rate of the 1,6linked product was determined as approximately 2.9 (3.0) times faster than that of the 1,1-linkage, and 6.9 (6.9) times faster than that of the 1,3/4-linkage, where the values in parenthesis are the previously determined ratio based on maximum intensities. The relative hydrolysis rate of the 1,1-linked product was determined as 4.9 times faster than the 1,6-linked product, and the 1,3/4-linked product was hydrolyzed 1.5 times faster than the 1,6-linked product. These relative hydrolysis rates would also explain why the 1,1linkage have not previously been observed, as it is a much better substrate compared to the 1,6-linked products, which the enzyme is well known for producing. The obtained rate constants were $\mathrm{k}_{1}=$ $0.4131 \mathrm{~s}^{-1}, \mathrm{k}_{2}=0.1197 \mathrm{~s}^{-1}, \mathrm{k}_{3}=0.3413 \mathrm{~s}^{-1}, \mathrm{k}_{4}=0.0498 \mathrm{~s}^{-1}, \mathrm{k}_{5}=$ $0.5183 \mathrm{~s}^{-1}, \mathrm{k}_{6}=0.1051 \mathrm{~s}^{-1}$ and $\mathrm{k}_{7}=0.1613 \mathrm{~s}^{-1}$.

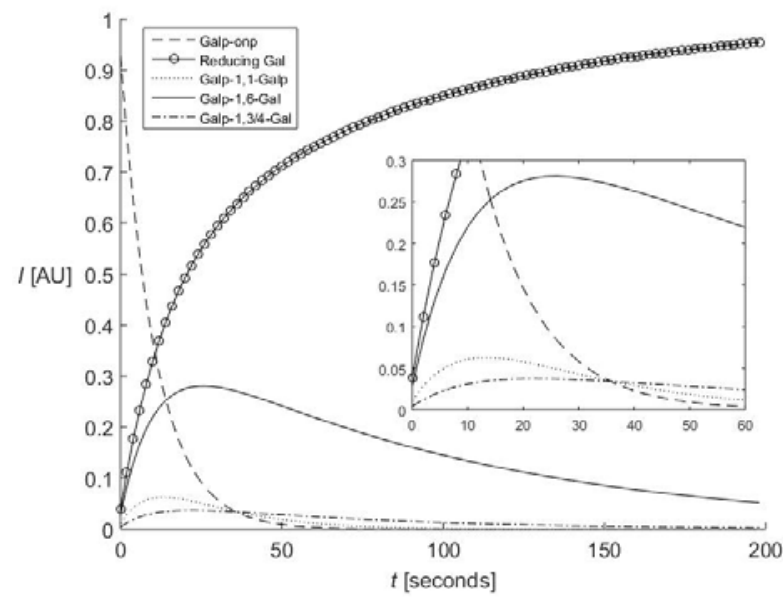

Figure 4. Plot of the model fits with the polarization decay removed. The insert is a zoom.

As evident from the data, some enzymatic conversion of the starting material had already occurred by the first acquisition. This would have taken place during the mixing of the substrate and the enzyme in the NMR tube, but as evident from figure 3 and 4, only approximately $8 \%$ of the substrate was converted at the time of the first acquisition. Furthermore, from the model fitting, the relative rates of formation and hydrolysis of each transglycosylation product could be determined.

\section{Conclusion}

Compared to other methods of detection, dDNP NMR can achieve both high sensitivity and high temporal resolution. Even though $\beta$-galactosidase is one of the most investigated carbohydrate converting enzymes, we discovered previously unknown intermediates of the reaction. It was possible to increase the knowledge of the enzyme, as it had not previously been reported to produce any non 1,6-linkages. Furthermore, the method could also be used to determine the relative transglycosylation rates producing each of the three observed intermediate products, and finally it was possible to approximate the relative rates of transglycosylation and hydrolysis. To improve the transfer speed and initialization of experiment, a transfer system like the one described in Bowen and Hilty (2008) could be implemented. ${ }^{26}$

Achieving this level of detail, sensitivity and temporal resolution can help further the understanding of enzymatic reactions, as is shown herein with one of the best described and most investigated carbohydrate converting enzymes. In this case, low-populated and short lived transglycosylation intermediates were observed, and especially the Galp-1,1-Galp would be difficult to detect using other conditions, as it is a much better substrate than the other transglycosylation products. This data also suggests that the hydrolysis and transglycosylation mechanism is more complex than previously described, as it goes through multiple low-populated short lived intermediates.

\section{ASSOCIATED CONTENT}

\section{Supporting Information}

The supporting information contains the experimental description of substrate synthesis and additional spectra.

The Supporting Information is available free of charge on the ACS Publications 
brief description

(file

type,

i.e.,

PDF)

brief description (file type, i.e., PDF)

\section{AUTHOR INFORMATION}

Corresponding Author

jduus@kemi.dtu.dk

Notes

The authors declare no competing financial interests.

\section{ACKNOWLEDGMENT}

David Teze is acknowledged for useful discussions. C.K. acknowledges the Novo Nordisk foundation for funding: Biotechnologybased synthesis and production research, program grant no 5371. The Danish National Research Foundation is acknowledged for funding the Center for Hyperpolarization in Magnetic Resonance (DNRF124).

\section{REFERENCES}

(1) Seeberger, P. H.; Werz, D. B. Nature 2007, 446, 1046-1051.

(2) Mano, M. C. R.; Neri-Numa, I. A.; da Silva, J. B.; Paulino, B. N.; Pessoa, M. G.; Pastore, G. M. Appl. Microbiol. Biotechnol. 2018, 102, 17-37.

(3) Ardenkjær-Larsen, J. H.; Fridlund, B.; Gram, A.; Hansson, G.; Hansson, L.; Lerche, M. H.; Servin, R.; Thaning, M.; Golman, K. Proc. Natl. Acad. Sci. U. S. A. 2003, 100, 10158-10163.

(4) Robillard, G.; Shaw, E.; Shulman, R. G. Proc Natl Acad Sci USA 1974, 71, 2623-2626.

(5) Withers, S. G.; Dombroski, D.; Berven, L. A.; Kilburn, D. G.; Miller, R. C.; J. Warren, R. A.; Gilkes, N. R. Biochem. Biophys. Res. Commun. 1986, 139, 487-494.

(6) Jensen, P. R.; Meier, S.; Ardenkjær-Larsen, J. H.; Duus, J. Ø.; Karlsson, M.; Lerche, M. H. Chem. Commun. (Camb). 2009, 5168-5170.

(7) Lee, Y.; Heo, G. S.; Zeng, H.; Wooley, K. L.; Hilty, C. J. Am. Chem. Soc. 2013, 135, 4636-4639.

(8) Meier, S.; Karlsson, M.; Jensen, P. R. ACS Sustain. Chem. Eng. 2017, 5, 5571-5577.
Keshari, K. R · Wilson, D. M.; Chen, A. P.; Bok, R ; Larson, P. E. Z.; Hu, S.; Van Criekinge, M.; Macdonald, J. M.; Vigneron, D. B.; Kurhanewicz, J. J. Am. Chem. Soc. 2009, 131, 17591-17596. Meier, S.; Karlsson, M.; Jensen, P. R.; Lerche, M. H.; Duus, J. Ø. Mol. Biosyst. 2011, 7, 2834-2836.

(11) Meier, S.; Jensen, P. R.; Duus, J. Ø. ChemBioChem 2012, 13, 308-310.

(12) Rodrigues, T. B.; Serrao, E. M.; Kennedy, B. W. C.; Hu, D.-E.; Kettunen, M. I.; Brindle, K. M. Nat. Med. 2013, 20, 93-97.

(13) Miclet, E.; Abergel, D.; Bornet, A.; Milani, J.; Jannin, S.; Bodenhausen, G. J. Phys. Chem. Lett. 2014, 5, 3290-3295.

(14) Raich, L.; Borodkin, V.; Fang, W.; Castro-López, J.; van Aalten, D. M. F.; Hurtado-Guerrero, R.; Rovira, C. J. Am. Chem. Soc 2016, 138, 3325-3332.

(15) Juers, D. H.; Matthews, B. W.; Huber, R. E. Protein Sci. 2012 21, 1792-1807.

(16) Wheatley, R. W.; Huber, R. E. Biochem. Cell Biol. 2015, 93, 531540.

(17) Egel, R. J. Theor. Biol. 1979, 79, 117-119.

(18) Huber, R. E.; Kurz, G.; Wallenfels, K. Biochemistry 1976, 15, 1994-2001.

(19) Chen, C. W.; Ou-Yang, C. C.; Yeh, C. W. Enzyme Microb. Technol. 2003, 33, 497-507.

(20) Brás, N. F.; Fernandes, P. A.; Ramos, M. J. J. Chem. Theory Comput. 2010, 6, 421-433.

(21) Rodriguez-Colinas, B.; De Abreu, M. A.; Fernandez-Arrojo, L.; De Beer, R.; Poveda, A.; Jimenez-Barbero, J.; Haltrich, D.; Ballesteros Olmo, A. O.; Fernandez-Lobato, M.; Plou, F. J. J. Agric. Food Chem. 2011, 59, 10477-10484.

(22) Hinz, S. W. A.; Verhoef, R.; Schols, H. A.; Vincken, J. P.; Voragen, A. G. J. Carbohydr. Res. 2005, 340, 2135-2143.

(23) Koto, S.; Inada, S.; Zen, S. Chem. Lett. 1980, 403-406.

(24) Hill, D. K.; Jamin, Y.; Orton, M. R.; Tardif, N.; Parkes, H. G.; Robinson, S. P.; Leach, M. O.; Chung, Y.-L.; Eykyn, T. R. NMR Biomed. 2013, 26, 1321-1325.

(25) Drachman, N.; Kadlecek, S.; Duncan, I.; Rizi, R. Phys. Chem. Chem. Phys. 2017, 19, 19316-19325.

(26) Bowen, S.; Hilty, C. Angew. Chemie Int. Ed. 2008, 47, 52355237. 


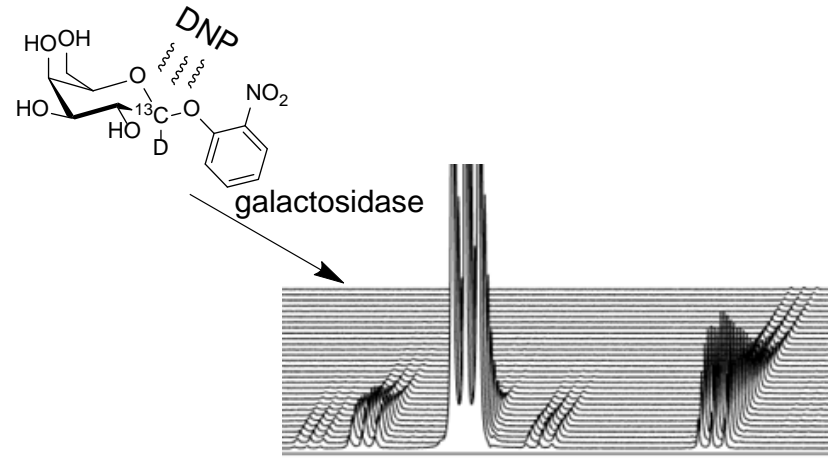

